\title{
Enantioselective Hydrosilylation with a Chiral $N$-Heterocyclic Carbene Complex of Rhodium(I) [1]
}

\author{
Sandra C. Zinner ${ }^{\mathrm{a}}$, Mei Zhang-Preße ${ }^{\mathrm{b}}$, Wolfgang A. Herrmann ${ }^{\mathrm{a}, \mathrm{b}}$, and Fritz E. Kühn ${ }^{\mathrm{a}, \mathrm{b}}$ \\ Contribution of the ${ }^{\mathrm{a}}$ Chair of Inorganic Chemistry and ${ }^{\mathrm{b}}$ Molecular Catalysis, Catalysis Research \\ Center of the Technische Universität München, Lichtenbergstr. 4, 85747 Garching, Germany \\ Reprint requests to Fritz E. Kühn. E-mail: fritz.kuehn@ch.tum.de
}

Z. Naturforsch. 2009, 64b, 1607 - 1611; received October 5, 2009

Dedicated to Professor Hubert Schmidbaur on the occasion of his $75^{\text {th }}$ birthday

Both enantiomers of the chiral rhodium-NHC complex [(4X,5X)-1,3-bis[2,6-diisopropyl-phenyl]4,5-ditert-butylimidazolidine-2-ylidene][1,5-cyclooctadiene]-iodo-rhodium(I) with $X=R, S$ were applied as catalysts for the asymmetric hydrosilylation of prochiral ketones. The influence of employed solvent, substrate, silane, and catalyst enantiomer on the catalytic activity and the enantioselectivity of the desired product was investigated.

Key words: Homogeneous Catalysis, Rhodium Complex, Enantioselective Hydrosilylation, $\mathrm{N}$-Heterocyclic Carbene Ligands

\section{Introduction}

Due to the increasing demand of enantiomerically pure compounds by the pharmaceutical industry, asymmetric catalysis developed to one of the fastest growing areas of research in synthetic chemistry. The asymmetric hydrosilylation represents a popular catalytic method for the reduction of prochiral ketones and imines to generate the corresponding alcohols and amines as shown in Scheme 1 [2].

Karstedt's catalyst is among the most active hydrosilylation catalysts known [3], but the exact composition and structure of its active species has not been determined as yet. Therefore, it is impossible to undertake specific modifications for its application in enantioselective hydrosilylation. Other active hydrosilylation catalysts such as transition metal phosphine or $N$-heterocyclic carbene (NHC) complexes have been developed, with phosphine complexes typically achieving higher activities [4]. However, the application of transition metal phosphine complexes for enantioselective hydrosilylation is limited due to their labile M-P bonds. The chiral information contained in the ligand often gets lost due to dissociation of the phospine during the catalytic cycle [5]. NHCs represent an attractive alternative for phosphines because they possess similar properties, but are stronger $\sigma$ donors $[6,7]$. Enantioselective NHC complexes generating high enantiomeric excesses have been reported for a variety of catalytic reactions, e. $g$. the iridiumcatalyzed hydrogenation of alkenes [8], rutheniumcatalyzed metathesis reactions [9], and rhodiumcatalyzed conjugate additions and hydosilylations [10]. The first example for the application of chiral rhodium(I)-NHC complexes as enantioselective hydrosilylation catalysts was reported by Herrmann et al. [11] who achieved quantitative yields and chiral inductions of up to $32 \%$ ee at temperatures as low as $-34{ }^{\circ} \mathrm{C}$ and found a remarkably high catalyst lifetime. Today, examples for transition metal NHC complexes are known that achieve very high enantioselectivities for the hydrosilylation of prochiral ketones [10c, 12].

The reaction mechanism of hydrosilylation reactions is not fully understood, but several catalytic cycles have been proposed [13]. Therefore, it is of great interest to study the influence of different reaction

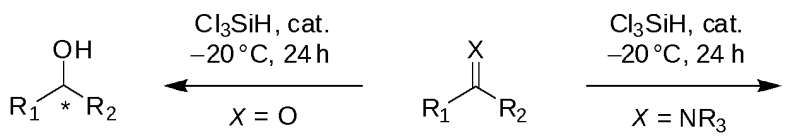

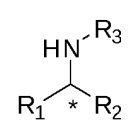

Scheme 1. Catalytic hydrosilylation of prochiral ketones and imines. 
$\mathrm{R}_{\mathrm{R}^{\prime}}^{\mathrm{O}}+10$ Silane $\stackrel{2 \text { mol-\% cat. }}{\longrightarrow} \frac{\mathrm{MeOH}}{\mathrm{NaOH}}$<smiles>[R]C([R])O</smiles>

Scheme 2. Investigated hydrosilylation reaction.

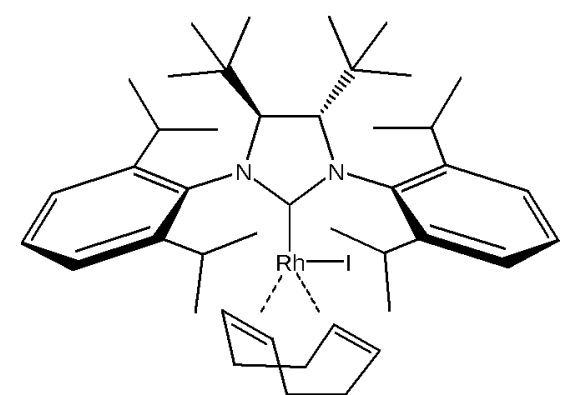

Fig. 1. Chiral rhodium(I)-NHC complex 1.

parameters on yield and enantiomeric excess (ee). In this work, we present the results obtained by investigating the influence of the solvent, the catalyst enantiomer, the silane, the substrate, and the temperature on yield and $e e$ values for the catalytic hydrosilylation of prochiral ketones [14]. The chiral catalyst $[(\mathrm{COD}) \mathrm{Rh}(\mathrm{NHC}) \mathrm{I}]$ with $\mathrm{NHC}=$ 1,3-bis(diisopropylphenyl)-( $X, X) 4,5$-bis(tert-butyl)imidazolidineylidene and $X=R$ or $S$ (1) [15] was employed for this study $((S, S)$-enantiomer $=(-)$-enantiomer as shown in Fig. 1).

\section{Results and Discussion}

To determine the activity and optical induction of $\mathbf{1}$ as a catalyst for hydrosilylation, the reaction shown in Scheme 2 was investigated.

\section{Solvent influence}

In homogeneous catalysis, the solubility of the reactants and the catalyst play a key role for the conversion of the reactants. Therefore, the activity of (-)-1 was first determined for the reaction of acetophenone with $\mathrm{Ph}_{2} \mathrm{SiH}_{2}$ in three solvents of different polarity toluene ( $\mu=0.36$ Debye), tetrahydrofurane $(\mu=1.63$ Debye), and dichloromethane ( $\mu=1.60$ Debye) [16] at r. t. The time-dependent yields are shown in Fig. 3.

The highest yield was reached when the reaction was carried out in tetrahydrofuran, while dichloromethane led to the lowest conversion. The observed differences cannot be correlated with the polarity of the solvents. Instead, the donor strength of the solvent could play a role since tetrahydrofuran

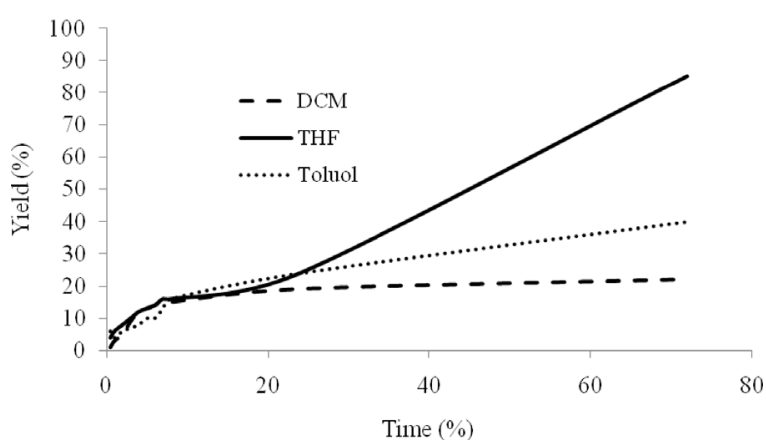

Fig. 3. Time-dependent yield in different solvents.

as the strongest donor leads to the highest activity whereas the weakest donor dichloromethane generates very low conversions. It may be possible that an initiation step such as the dissociation of $\mathrm{I}^{-}$occurs, generating a cationic complex which can be stabilized by the coordination of tetrahydrofuran. The labile solvent molecule would easily be replaced by the substrate in the following step.

\section{Influence of the catalyst enantiomer}

For many naturally occurring reactions that involve chiral catalysts it has been shown that the choice of the enantiomer can significantly influence the result due to the importance of the transition state. For this reason we examined the hydrosilylation of acetophenone with $\mathrm{Ph}_{2} \mathrm{SiH}_{2}$ in the presence of the (-)- and (+)-enantiomer of the catalyst. The time-dependent yield for both cases is illustrated in Fig. 4. Interestingly, the (-)-enantiomer leads to a much higher yield than the (+)-enantiomer.

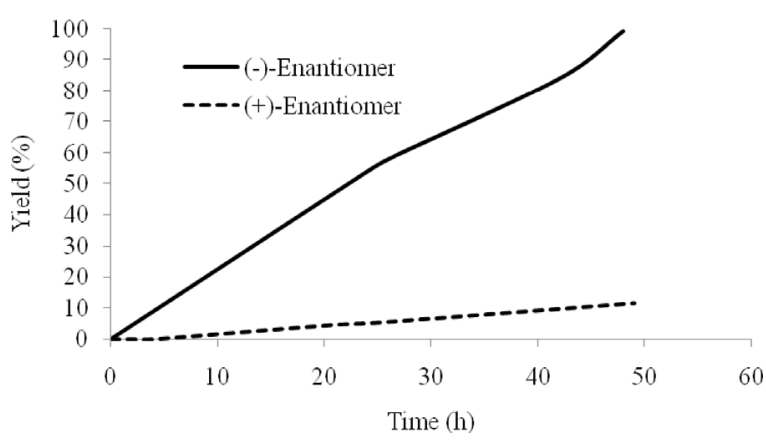

Fig. 4. Time-dependent conversion in the presence of different enantiomers of the catalyst. 


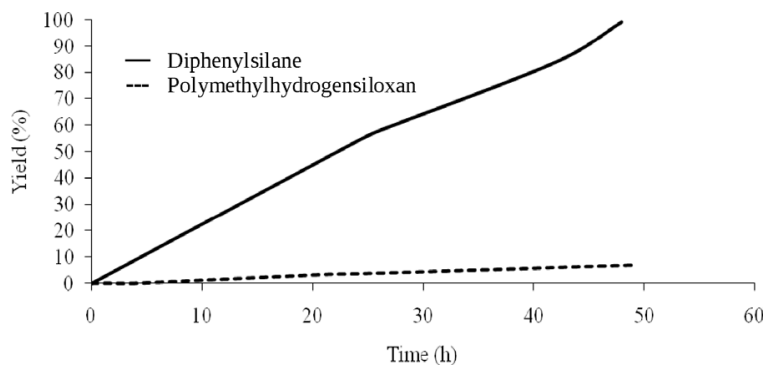

Fig. 5. Time-dependent conversion of the hydrosilylation of benzophenone with $\mathrm{Ph}_{2} \mathrm{SiH}_{2}$ and polymethylhydrogensiloxane.

Since the solubility of both complexes is the same, and identical reaction conditions were applied, it can be assumed that the energy barrier for the formation of the transition state in the (-)-enantiomer might be lower. Calculations are currently underway to support this assumption.

\section{Silane influence}

In order to evaluate the catalytic performance of new hydrosilylation catalysts, diphenylsilane is typically employed in the published literature. However, the interest of chemical industry in the hydrosilylation with this silane is rather limited. Therefore, polymethylhydrogensiloxane $\left(\left(\mathrm{H}_{3} \mathrm{C}\right)_{3} \mathrm{SiO}\left[\mathrm{Si}\left(\mathrm{CH}_{3}\right)_{2} \mathrm{O}\right]_{n} \mathrm{Si}\left(\mathrm{CH}_{3}\right)_{3}\right)$ was used to hydrosilylate acetophenone. Fig. 5 shows the time-dependent yield for the hydrosilylation of acetophenone with diphenylsilane versus polymethylhydrogensiloxane.

It is obvious from Fig. 5 that the hydrosilylation with polymethylhydrogensiloxane only generates very small amounts of the desired alcohol while the hydrosilylation with diphenylsilane reaches quantitative yield after $48 \mathrm{~h}$.

\section{Variation of the substrates}

To investigate the influence of the substrate on the activity and optical induction of (-)-1, acetophenone (A), $\alpha, \alpha, \alpha$-trifluoromethylacetophenone $(\mathbf{B}), 4$ trifluormethylacetophenone $(\mathbf{C})$, acetonaphtone (D), and 4-chloro-acetophenone (E) were employed at different temperatures. Yields and enantiomeric excesses are summarized in Table 1.

When the standard substrate A was employed as the substrate for the hydrosilylation reaction at room temperature, almost quantitative yield, but very low enantioselectivity ( $4 \% e e$ ) was reached after $48 \mathrm{~h}$. It is known that by lowering the temperature, thermo-
Table 1. Yields and enantiomeric excesses for the hydrosilylation of $\mathbf{A}-\mathbf{E}$ with $\mathrm{Ph}_{2} \mathrm{SiH}_{2}$ at varying temperatures in the presence of (-)-1.

\begin{tabular}{cllccrc}
\hline Substrate & $\mathrm{R}$ & $\mathrm{R}^{\prime}$ & $t(\mathrm{~h})$ & Yield $(\%)$ & $T\left({ }^{\circ} \mathrm{C}\right)$ & $\%$ ee \\
\hline A & $\mathrm{Ph}$ & $\mathrm{CH}_{3}$ & 48 & 99 & 25 & 4 \\
A & $\mathrm{Ph}$ & $\mathrm{CH}_{3}$ & 48 & 9 & 0 & 7 \\
A & $\mathrm{Ph}$ & $\mathrm{CH}_{3}$ & 72 & 2 & -40 & 9 \\
B & $\mathrm{Ph}$ & $\mathrm{CF}_{3}$ & 3 & 100 & 25 & 1 \\
B & $\mathrm{Ph}$ & $\mathrm{CF}_{3}$ & 48 & 73 & 0 & 5 \\
B & $\mathrm{Ph}$ & $\mathrm{CF}_{3}$ & 28,5 & 17 & -40 & 6 \\
C & 4-CF $-\mathrm{Ph}$ & $\mathrm{CH}_{3}$ & 3 & 94 & 25 & 73 \\
D & 2-Naphtyl & $\mathrm{CH}_{3}$ & 72 & 28 & 25 & 5 \\
D & 2-Naphtyl & $\mathrm{CH}_{3}$ & 48 & 19 & 0 & 8 \\
D & 2-Naphtyl & $\mathrm{CH}_{3}$ & 72 & 2 & -40 & 11 \\
E & 4-Cl-Ph & $\mathrm{CH}_{3}$ & 48 & 31 & 25 & 5 \\
\hline
\end{tabular}

dynamic effects become more significant in catalytic reactions, and increased enantioselectivities can be achieved. However, only a small increase of the enantiomeric excess $(7 \% e e)$ and a drastic decrease of the yield (9\% after $48 \mathrm{~h}$ ) was observed in case of $\mathbf{A}$ when decreasing the temperature to $0{ }^{\circ} \mathrm{C}$. In case of $\mathbf{B}$, an activated substrate, a significantly increased catalytic activity was observed. After three hours at r.t. the product was obtained quantitatively, enantiselectivity, however, was completely lost $(1 \%$ ee $)$. When the same reaction was carried out at $0{ }^{\circ} \mathrm{C}$, the enantioselectivity of the catalytic reaction was still very small (5\% ee), and the activity dropped significantly. After $48 \mathrm{~h} 73 \%$ of the corresponding alcohol was obtained. At $-40{ }^{\circ} \mathrm{C}$ the yield decreased further, and only $17 \%$ alcohol was detected after $28.5 \mathrm{~h}$. When employing the substrate $\mathbf{C}$ which contains an electron-withdrawing substituent attached to the phenyl ring, major differences to $\mathbf{B}$, bearing an electron-withdrawing substituent bound directly to the ketone group, were observed. After $3 \mathrm{~h}$ at r. t., a yield of $94 \%$ and an enantiomeric excess of $73 \%$ were detected. The hydrosilylation of $\mathbf{D}$, a deactivated substrate, at r. t. leads to $28 \%$ of the corresponding alcohol after $72 \mathrm{~h}$. Lowering the temperature to $0{ }^{\circ} \mathrm{C}$ results in a slight increase of the obtained $e e$, again associated with a decrease of the yield ( $19 \%$ after $24 \mathrm{~h})$. At $-40{ }^{\circ} \mathrm{C}$ the reaction does not occur. When employing the deactivated substrate $\mathbf{E}$, a yield of $31 \%$ and an enantiomeric excess of $5 \%$ was detected after a reaction time of $48 \mathrm{~h}$ at r.t. In summary, we observed high yields for the standard substrate acetophenone and the activated substrates $\mathbf{B}$ and $\mathbf{C}$ with the expected increased activity in case of $\mathbf{B}$ and $\mathbf{C}$ and low yields for the deactivated substrates $\mathbf{D}$ and $\mathbf{E}$. The catalyst did not transfer its chiral information into the product, with the sole exception of the hydrosilylation of $\mathbf{C}$. Reduction of the reac- 
tion temperature did not significantly improve stereoselectivity in any case, but always resulted in very low yields.

\section{Conclusion}

The catalytic activity and enantioselectivity of the complexes [(4X,5X)-1,3-bis[2,6-diisopropylphenyl]4,5-ditert-butylimidazolin-2-ylidene][1,5-cyclooctadiene]-iodorhodium(I) with $X=R$ or $S$ for the hydrosilylation of prochiral ketones was investigated. Activity and enantiomeric excess were found to depend on solvent, substrate, silane, and catalyst enantiomer employed. Among the solvents tested, tetrahydrofuran - as the strongest donor - led to the highest conversion. Interestingly, the (-)-enantiomer of $\mathbf{1}$ displayed a much higher catalytic activity as the corresponding (+)-enantiomer. By comparing the hydrosilylation of different substrates it was shown that the catalytic activity of the (-)-enantiomer of $\mathbf{1}$ decreases in the following order: activated substrates (B and $\mathbf{C}$ ) $>$ acetophenone $(\mathbf{A})>$ deactivated substrates $(\mathbf{D}$ and E). Significant enantioselectivity was only achieved for 4-trifluormethylacetophenone (C). Further studies, particularly including a more detailed study of the initiation step will be performed in our group.

\section{Experimental Section}

\section{Catalyst synthesis}

Compound $\mathbf{1}$ was synthesized according to a literature procedure [6]. GC spectra for determination of the catalytic result were measured on a Varian gas chromatograph $\mathrm{CP}$ 3800 (column: FactorFour VF-5 ms) equipped with an FID detector.

\section{General procedure for catalytic reactions}

Compound $1(0.6 \mathrm{mmol})$ was dissolved in the appropriate solvent $(2 \mathrm{~mL})$. The appropriate ketone $(10 \mathrm{mmol})$ and diethylenglycoldibutylether $(375 \mu \mathrm{L})$ were added as internal GC standards. Then the silane $(60 \mathrm{mmol})$ was injected. After a certain time, a sample of $1 \mathrm{~mL}$ was taken from the reaction mixture. Methanol $(1 \mathrm{~mL})$ and sodium hydroxide $(1 \mathrm{~mL}, 0.5 \mathrm{M})$ were added to deprotect the silylated products for analysis. After ten minutes of stirring, the product was extracted using diethyl ether and filtered through glass wool. The ratio of products and starting materials were determined by GC analysis.

\section{Acknowledgement}

This work was supported by the Elitenetzwerk Bayern (scholarship for S.C.Z.).
[1] $N$-Heterocyclic carbenes 92. Part 91: A. Bittermann, E. Herdtweck, P. Härter, W. A. Herrmann, Organometallics 2010, in press.

[2] E. N. Jacobsen, A. Pfaltz, H. Yamamoto, Comprehensive Asymmetric Catalysis, Vol. I-III, Springer, Heidelberg 1999.

[3] a) B.D. Karstedt, U.S. Patent, 3, 775, 452, 1973; b) B.N. Willing, U.S. Patent, 3, 419, 593, 1986. c) B. A. Ashby, F. J. Modic, U.S. Patent, 4, 228, 345, 1981.

[4] a) D. H. Appella, Y. Moritani, R. Shintani, E. M. Ferreira, S.L. Buchwald, J. Am. Chem. Soc. 1999, 121, 9473 - 9474 . b) Y. Moritani, D. H. Appella, V. Jurkauskas, S. L. Buchwald, J. Am. Chem. Soc. 2000, 122, $6797-6798$

[5] a) C. M. Crudden, D. P. Allen, Coord. Chem. Rev. 2004, 248, 2247-2273. b) M.-T. Lee, C.-H. Hu, Organometallics 2004, 23, 976-983. c) W. A. Herrmann, Angew.Chem. 2002, 114, 1342 -1362; Angew. Chem. Int. Ed. 2002, 41, $1290-1309$.

[6] J. W. Faller, P. P. Fontaine, Organometallics 2006, 25, $5887-5898$.

[7] S.C. Zinner, W. A. Herrmann, F.E. Kühn, Tetrahedron: Asymmetry 2008, 19, $1532-1535$.
[8] M. C. Perry, X. H. Cui, M. T. Powell, D. R. Hou, J. H. Reibenspies, K. J. Burgess, J. Am. Chem. Soc. 2003, $125,113-123$.

[9] T. J. Seiders, D. W. Ward, R.H. Grubbs, Org. Lett. 2001, 3, 3225-3228.

[10] a) J. M. Becht, E. Bappert, G. Helmchen, Adv. Synth. Catal. 2005, 347, 1495-1498; b) W. L. Duan, M. Shi, G. B. Rong, Chem. Commun. 2003, 2916-2917; c) L. H. Gade, V. Cesar, S. Bellemin-Laponnaz, Angew. Chem. 2004, 116, 1036-1039; Angew. Chem. Int. Ed. 2004, 43, $1014-1017$.

[11] W. A. Herrmann, L. J. Goossen, C. Kocher, G. R. J. Artus, Angew. Chem. 1996, 108, 2980-2982; Angew. Chem., Int. Ed. Engl. 1996, 35, $2805-2807$.

[12] a) W.-L. Duan, M. Shi, G.-B. Rong, Chem. Commun. 2003, 2916-2917; b) D. R. Snead, H. Seo, S. Hong, Curr. Org. Chem. 2008, 12, $1370-1387$; c) A. T. Normand, K. J. Cavell, Eur. J. Inorg. Chem. 2008, 18, $2781-2800$.

[13] a) H. Nishiyama, K. Itoh, Catalytic Asymmetric Synthesis (Ed.: I. Ojima), Wiley-VCH, New York 2000, pp. 111; b) O. Riant, N. Mostefa, J. Courmarcel, Synthesis, 2004, 2943-2958; c) N. Schneider, M. Finger, C. Haferkemper, S. Bellemin-Laponnaz, P. Hof- 
mann, L. H. Gade, Angew. Chem. 2009, 121, $1637-$ 1641; Angew. Chem. Int. Ed. 2009, 48, 1609-1613; d) I. Ojima, M. Nihonyanagi, T. Kogure, M. Kumagai, S. Horiuchi, K. Nakatsugawa, J. Organomet. Chem. 1975, 94, 449-461; e) I. Ojima, T. Kogure, M. Kumagai, S. Horiuchi, T. Sato, J. Organomet. Chem. 1976, 122, 83-97; f) G.Z. Zheng, T. H. Chan, Organometallics 1995, 14, 70-79; g) H. Brunner,
M. Weber, M. Zabel, J. Organomet. Chem. 2003, 684, $6-12$; h) S. Díez-González, N. Marion, S. P. Nolan, Cem. Rev. 2009, 109, 3612-3676.

[14] S.C. Zinner, Dissertation, Technische Universität München, München 2009.

[15] S. C. Zinner, W. A. Herrmann, F. E. Kühn, J. Organomet. Chem. 2008, 693, 1543-1546.

[16] RÖMPP Online, Georg Thieme Verlag, Stuttgart 2009. 